
2

\title{
Thermo-reversible inhibition makes aqualysin 1 from Thermus aquaticus a potent tool for studying the contribution of the wheat gluten network to the crumb texture of fresh bread
}

\author{
Annelien E. VERBAUWHEDE*1, Marlies A. LAMBRECHT ${ }^{1}$, Ellen FIERENS ${ }^{1,1}$, Senne HERMANS ${ }^{1, I I}$, \\ Oksana SHEGAY², Kristof BRIJS ${ }^{1}$ and Jan A. DELCOUR ${ }^{1}$
}

Running title: Impact of Aqualysin 1 on the gluten network and texture of fresh bread

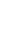

${ }^{1} \mathrm{KU}$ Leuven, Laboratory of Food Chemistry and Biochemistry, Leuven Food Science and Nutrition

Research Centre (LFoRCe), Kasteelpark Arenberg 20, B-3001 Leuven, Belgium.

${ }^{2}$ Competence Center for Fermentation. Puratos Group. Rue Bourrie 12, Andenne, Belgium

'Present address: Flanders' Food, Wetenschapsstraat 14A, B-1040 Brussel, Belgium

"Present address: Sildi, Grauwmeer 1, B-3000 Leuven, Belgium

*Corresponding author. Phone: (+32)-16-376408. Fax: (+32)-16-321997.

E-mail: annelien.verbauwhede@kuleuven.be

E-mail other authors : marlies.lambrecht@kuleuven.be; ellen.fierens@flandersfood.com; senne.hermans@hotmail.com; oshegay@puratos.com; kristof.brijs@kuleuven.be; jan.delcour@kuleuven.be

Keywords: peptidase; serine peptidase inhibitors; thermo-active; bread; gluten functionality 
24 Abstract

25 The thermo-active serine peptidase aqualysin 1 (Aq1) of Thermus aquaticus was applied in bread making to study the relative contribution of thermoset gluten to bread crumb texture. Aq1 is

27 active between $30{ }^{\circ} \mathrm{C}$ and $90{ }^{\circ} \mathrm{C}$ with an optimum activity temperature of around $65^{\circ} \mathrm{C}$. It is 28 inhibited by wheat endogenous serine peptidase inhibitors during dough mixing and 29 fermentation and starts hydrolyzing gluten proteins during baking above $80^{\circ} \mathrm{C}$ when the enzyme 30 is no longer inhibited and most of the starch is gelatinized and contributes to structure formation.

31 Aq1 activity reduced the molecular weight of gluten proteins and significantly increased their

32 extractability in sodium dodecyl sulfate containing medium. While it had no impact on the 33 specific bread volume and only limited impact on hardness, cohesiveness, springiness, resilience 34 and chewiness, it impacted bread crumb coherence. We conclude that starch has a greater 35 impact on crumb texture than thermoset gluten.

\section{Introduction}

37 The unique bread making properties of wheat are ascribed to the visco-elastic properties of its 38 gluten proteins. They make up about $80 \%$ of the total protein content and are divided in two groups: monomeric gliadins [molecular weight (MW) of $30-80 \mathrm{k}$ ] and polymeric glutenins (MW of $80 \mathrm{k}$ to more than twenty million) (Shewry, Tatham, Forde, Kreis, \& Miflin, 1986; Veraverbeke

$41 \&$ Delcour, 2002). Gliadins are subdivided in $\alpha$-, $\gamma$ - and $\omega$-gliadins. The $\alpha$ - and $\gamma$-gliadins contain

42 cysteine residues which are connected through intramolecular disulfide (SS) bonds. $\omega$-Gliadins

43 lack cysteine residues (Delcour, Joye, Pareyt, Wilderjans, Brijs, \& Lagrain, 2012; Shewry, Tatham, 
44 Forde, Kreis, \& Miflin, 1986; Wieser, 2007). Glutenin consists of subunits (GS) which are

45 interconnected by SS bonds. GS contain intramolecular SS bonds and have at least one (free)

46 cysteine residue which enables them to form intermolecular SS bonds (D'Ovidio \& Masci, 2004;

47 Lindsay \& Skerritt, 1999; Megan \& Skerritt, 1999; Shewry \& Tatham, 1997; Shewry, Tatham,

48 Forde, Kreis, \& Miflin, 1986).

49 When wheat flour is mixed with an appropriate amount of water, a cohesive visco-elastic gluten

50 network is formed ( $H$. Singh \& MacRitchie, 2001; Song \& Zheng, 2007; Veraverbeke \& Delcour,

51 2002). This network retains the gas produced by yeast during fermentation and expansion.

52 During baking, at temperatures below $40{ }^{\circ} \mathrm{C}$ reversible changes take place (Lefebvre, Popineau,

53 Deshayes, \& Lavenant, 2000). At higher temperatures (up to $90^{\circ} \mathrm{C}$ ), glutenin forms a network

54 based on intermolecular SS bonds (Delcour \& Hoseney, 2010; Lagrain, Brijs, Veraverbeke, \&

55 Delcour, 2005; Schofield, Bottomley, Timms, \& Booth, 1983). At temperatures exceeding $90{ }^{\circ} \mathrm{C}$,

56 in addition to the above, gliadins are covalently incorporated into the gluten structure mainly

57 through sulfhydryl (SH)-SS exchange reactions (Lagrain, Thewissen, Brijs, \& Delcour, 2008).

58 In the baking process, starch gelatinizes and a thermoset gluten network is formed. Starch

59 gelatinization [i.e. loss of its birefringent properties (Delcour \& Hoseney, 2010)] and the

60 phenomena which accompany it (including swelling of the starch granules, water uptake, and

61 leaching of amylose) result in a sharp increase in viscosity and migration of plasticizing water

62 from the gluten network to starch (Delcour \& Hoseney, 2010; Goesaert, Brijs, Veraverbeke,

63 Courtin, Gebruers, \& Delcour, 2005; A. P. Singh \& Bhattacharya, 2005). The further expansion of

64 carbon dioxide gas and evaporation of ethanol and water cause rupture of the starch-protein 
matrix that surrounds the gas cells. These phenomena cause the transformation of a dough (a foam) into a gas continuous crumb by the end of the oven rise (Delcour \& Hoseney, 2010; Fan, Mitchell, \& Blanshard, 1999; Goesaert, Brijs, Veraverbeke, Courtin, Gebruers, \& Delcour, 2005; Scanlon \& Zghal, 2001; A. P. Singh \& Bhattacharya, 2005). Although the changes in starch and gluten proteins have been described, little is known about the relative contribution of both polymer types to bread crumb texture.

Endopeptidases generally already hydrolyze gluten to some degree during dough mixing and fermentation. Their action impairs dough rheology, its gas retention capacity and the crumb structure and specific volume of the resultant bread. To avoid dough structure collapse before oven spring, peptidase activity should be limited. However, appropriate peptidase use can result in soft fresh bread crumb and delay crumb firming and the subsequent increase of its chewiness during storage (Caballero, Gomez, \& Rosell, 2007; Indrani, Prabhasankar, \& Venkateswara Rao, 2003; Mathewson, 2000). In the present work, we used the thermo-active endopeptidase aqualysin 1 (Aq1; EC 3.4.21.111) for studying the importance of the gluten network for bread texture. This alkaline serine peptidase which belongs to the subtilisin-type peptidases is secreted by the thermophilic bacteria Thermus aquaticus. At pH 6 and 7, Aq1 has respectively about 40\% and $60 \%$ of its optimal activity at pH 10 (Matsuzawa, Tokugawa, Hamaoki, Mizoguchi, Taguchi, Terada, et al., 1988). Aq1 is optimally active at $70^{\circ} \mathrm{C}$ (Matsuzawa, et al., 1988; Rawlings, Barrett, \& Bateman, 2010) which would imply that it is active in the time frame during which starch gelatinization, dough / crumb transition and gluten polymerization occur. Also, as wheat flour contains serine peptidase inhibitors (Di Maro, Farisei, Panichi, Severino, Bruni, Ficca, et al., 2011; Mundy, Hejgaard, \& Svendsen, 1984; Odani, Koide, \& Ono, 1986; Østergaard, Rasmussen, 
Roberts, \& Hejgaard, 2000; Poerio, Di Gennaro, Di Maro, Farisei, Ferranti, \& Parente, 2003), we speculated that its activity during the dough and early baking stages would be very limited and that its inhibition, if any, would be thermo-reversible. In other words, we reasoned that, if the above proved to be true, use of Aql may help us to understand the importance of the thermoset gluten network for bread crumb and texture. To that end, we investigated the Aq1 activity at different temperatures in the presence of wheat flour proteins extracted in a dilute salt solution and its impact on gluten network formation during baking and on bread crumb texture.

\section{Materials and methods}

\subsection{Materials}

Crousti wheat flour [12.0\% protein; $14.0 \%$ moisture] was from Dossche Mills (Deinze, Belgium) and commercial gluten [Amygluten; 77.0\% protein ( $\mathrm{N} \times 5.7) ; 6.0 \%$ moisture] from Syral (Aalst, Belgium). Salt and sugar were from a local supermarket. Fresh yeast was from AB Mauri (Merelbeke, Belgium). All chemicals were at least of analytical grade. Acetic acid, sodium dodecyl sulfate (SDS), dithiothreitol (DTT), urea, disodium hydrogen phosphate and sodium dihydrogen phosphate were from VWR International (Leuven, Belgium). Bovine milk $\alpha$-lactalbumin was from Acros Organics (Geel, Belgium). All other chemicals, reagents and molecular mass markers were from Sigma-Aldrich (Bornem, Belgium). Aq1 was from Puratos (Groot-Bijgaarden, Belgium).

\subsection{Determination of moisture and protein content}

Moisture content was determined according to AACC method 44-15.02 (AACC). Protein contents were obtained by an adaptation of the AOAC method 990.03 (AOAC, 1995) to an automated Dumas protein analysis system (EAS Vario Max Cube, Elementar, Hanau, Germany). 


\subsection{The impact of wheat flour extract on aqualysin I activity}

The presence or absence of serine peptidase inhibitors in wheat flour was investigated with an assay. Wheat flour extract (WFE) was prepared by shaking (15 min) $15.0 \mathrm{~g}$ wheat flour with 100 $\mathrm{ml}$ sodium acetate buffer (50 mmol/l; $\mathrm{pH} \mathrm{5.5)} \mathrm{and} \mathrm{recovered} \mathrm{by} \mathrm{centrifugation} \mathrm{[15} \mathrm{min;} \mathrm{room}$ temperature (RT); 3,000 g]. It contained $1.8 \mathrm{mg} / \mathrm{ml}( \pm 0.1 \mathrm{mg} / \mathrm{ml})$ protein $(\mathrm{N} \times 6.25)$. Aq1 solution (25 $\mu$ l containing $1.00 \mathrm{U}$ of enzyme activity, see below for its definition) was preincubated with $25 \mu \mathrm{l}$ deionized water or WFE for $30 \mathrm{~min}$. Next, $70 \mu \mathrm{l}$ sodium carbonate buffer $(50 \mathrm{mmol} / \mathrm{l} ; \mathrm{pH}$ 10.0) and $70 \mu \mathrm{l}$ substrate solution (1.6 mg N-succinyl-ala-ala-pro-phe-p-nitroanilide in $1.0 \mathrm{ml}$ of the same buffer) were added. After incubation for $20 \mathrm{~min}$ at different temperatures, the absorbance of $p$-nitroaniline was measured colorimetrically at $415 \mathrm{~nm}$ (100 $\mu \mathrm{l}$ in a microtiter plate at RT). Under these assay conditions, $1.0 \mathrm{U}$ Aq1 is the amount of enzyme which at $50{ }^{\circ} \mathrm{C}$ and in the presence of water instead of WFE results in an absorbance value of 1.000. Absorbance values were converted to concentrations of $p$-nitroaniline using a calibration curve constructed with the same buffer. The absorbance of each sample was corrected for the absorbance of the substrate in absence of Aq1 (50 $\mu$ l deionized water, $70 \mu$ l buffer and $70 \mu$ l substrate solution).

\subsection{Bread making}

Breads were made according to a straight-dough method (Finney, 1984). The dough recipe consisted of wheat flour (100.0 g; $14.0 \%$ moisture), $5.30 \mathrm{~g}$ yeast, $1.50 \mathrm{~g}$ sodium chloride, $6.00 \mathrm{~g}$ sugar, $59.0 \mathrm{ml}$ deionized water [i.e. the Farinograph water absorption determined with AACC method 38-20.01 (AACC)] and 0.25 g calcium propionate. Aq1 dough contained $150 \pm 5 \mathrm{U} / \mathrm{g}$ flour protein. Mixing for $225 \mathrm{~s}$ [optimal mixing time obtained from Mixograph analysis with AACC 
method 54-40.02 (AACC)] at $23^{\circ} \mathrm{C}$ in a $100 \mathrm{~g}$ pin mixer (National Manufacturing, Lincoln, NE, USA) was followed by fermentation ( $90 \mathrm{~min} ; 30^{\circ} \mathrm{C}$; $90 \%$ relative humidity) in a fermentation cabinet (National Manufacturing). After $52 \mathrm{~min}$ and $77 \mathrm{~min}$ of fermentation, the dough was passed through a dough sheeter (National Manufacturing). Fermentation was followed by final sheeting, molding and proofing (36 $\mathrm{min} ; 30^{\circ} \mathrm{C} ; 90 \%$ relative humidity). After proofing, doughs were baked (24 min; $215^{\circ} \mathrm{C}$ ) in a rotary oven (National Manufacturing) and cooled to RT over a $150 \mathrm{~min}$ period. Bread volume was measured with a VolScan Profiler (Stable Micro Systems, Goldaming, UK). In the model system designed to determine the onset temperature of Aq1 activity, aliquots of proofed dough $(0.6 \mathrm{~g})$ were kept in closed containers at temperatures ranging from $50{ }^{\circ} \mathrm{C}$ to $95^{\circ} \mathrm{C}$ for $15 \mathrm{~min}$ and immediately cooled on ice.

\subsection{Rapid visco analyzer analysis}

The impact of Aq1 on the properties of gluten during heat-treatment was investigated with a rapid visco analyzer (RVA) essentially as in Lagrain et al. (2005). To a quantity of commercial gluten corresponding to $4.25 \mathrm{~g}$ protein $(\mathrm{N} \times 5.7)$ in a RVA cup, water was added to obtain a total weight of $25.00 \mathrm{~g}$. When Aql solution (11.0 or $22.0 \mathrm{U} / \mathrm{g}$ protein) was added, this was done prior to adding water to obtain a total weight as above. After homogenizing the suspension in an RVA4D (Newport Scientific, Sydney, Australia) (20 s; 900 rpm) device, it was subjected to viscosity measurement with a temperature-time profile that mimics bread baking. In short, samples were first heated to $40{ }^{\circ} \mathrm{C}$ in $1 \mathrm{~min}$ and then to $95^{\circ} \mathrm{C}$ in $14 \mathrm{~min}$. They were subsequently held at $95^{\circ} \mathrm{C}$ for $40 \mathrm{~min}$ and cooled to $50{ }^{\circ} \mathrm{C}$ in $7 \mathrm{~min}$. The temperature profile ended with a holding phase at $50{ }^{\circ} \mathrm{C}$ for $13 \mathrm{~min}$. During this temperature-time profile, the RVA paddle was rotated at $160 \mathrm{rpm}$. 


\subsection{Baking of model systems}

151 To investigate the role of both starch and gluten during bread crumb formation, dough balls 152 containing only gluten (GD) or gluten and starch (GSD) were made. Gluten dough (GD) samples 153 made from commercial gluten $(8.6 \mathrm{~g} \mathrm{dm})$ and $4.2 \mathrm{ml}$ water or Aql solution containing $150 \pm 5 \mathrm{U} / \mathrm{g}$ 154 gluten protein were kneaded by hand $\left(210 \mathrm{~s} ; 23^{\circ} \mathrm{C}\right)$ and baked $\left(13 \mathrm{~min} ; 232^{\circ} \mathrm{C}\right)$ in a rotary oven 155 (National Manufacturing). Gluten-starch doughs (GSD) consisted of commercial gluten (2.15 g $156 \mathrm{dm})$, starch $(6.45 \mathrm{~g} \mathrm{dm}$ ) and $6.32 \mathrm{ml}$ water or Aql solution containing $150 \pm 5 \mathrm{U} / \mathrm{g}$ gluten protein. 157 They were mixed (330 s) in a $10 \mathrm{~g}$ pin mixer (National Manufacturing) and baked (13 min; $\left.232^{\circ} \mathrm{C}\right)$ 158 in a rotary oven (Model Hearth, National Manufacturing). Pictures of the baked products were 159 taken the next day.

\subsection{Size exclusion high performance liquid chromatography}

161 Dough, fermented dough and bread crumb were frozen in liquid nitrogen, freeze dried, grinded 162 and sieved $(250 \mu \mathrm{m})$. Samples (1.0 $\mathrm{mg}$ protein) were extracted with $1.0 \mathrm{ml}$ solution A [sodium 163 phosphate buffer (50 mmol/l; $\mathrm{pH} 6.8$ ) containing $2.0 \%$ SDS and $40.0 \mathrm{mg} / \mathrm{l}$ phenylmethylsulfonyl 164 fluoride] or solution B [i.e. solution A also containing $2.0 \mathrm{M}$ urea and $1.0 \% \mathrm{DTT}$ ]. Extraction with 165 solution B was performed under nitrogen atmosphere to avoid DTT oxidation. Samples were 166 shaken (60 min; RT) and centrifuged (10 min; RT; 10,000 g). The resultant supernatants were 167 filtered (Millex-HP, $0.45 \mu \mathrm{m}$, polyether-sulfone, Millipore, Carrigtwohill, Ireland) and aliquots (20 $168 \mu \mathrm{l}$ ) separated by size exclusion high performance liquid chromatography (SE-HPLC) (LC-2010 169 system; Shimadzu, Kyoto, Japan) on a Biosep-SEC-S4000 (pore size 500 Ä, Phenomenex, Torrance, 170 CA, USA) column. The eluent was sodium phosphate buffer (50 mmol/l; pH 6.8) containing $2.0 \%$ 
171 SDS (flow rate $1.0 \mathrm{ml} / \mathrm{min} ; 30^{\circ} \mathrm{C}$ ). Elution was monitored at $214 \mathrm{~nm}$. Protein extractable in SDS

172 containing medium (SDS-EP) was expressed as a percentage of total peak area of proteins

173 extracted from control dough under reducing conditions. Protein markers were ribonuclease $A$

174 (13.7 k), bovine milk $\alpha$-lactalbumin (14.4 k), soybean trypsin inhibitor $(20.2 \mathrm{k})$, $\alpha$ -

175 chymotrypsinogen A from bovine pancreas (25 k), bovine erythrocytes carbonic anhydrase (30 k),

176 aldolase (40 k), chicken egg white ovalbumin (45 k), catalase (56 k), bovine serum albumin (66 k),

177 and phosphorylase b (97 k).

\subsection{Texture profile analysis}

After 150 min of cooling, cylinders of crumb (diameter $30 \mathrm{~mm}$ ) were removed with a sharp borer from the three most inner slices (thickness $25 \mathrm{~mm}$ ) of three bread replicates. The resultant nine

181 cylindrical bread crumb samples were subjected to texture profile analysis (TPA) using an Instron

182 (Norwood, MA, USA) 3342 device essentially as described by Bourne (1978). Crumb cylinders 183 were compressed twice to $50 \%$ of their original height with a cylindrical probe (diameter $75 \mathrm{~mm}$ ) 184 at $100 \mathrm{~mm} / \mathrm{min}$ with a $50 \mathrm{~N}$ load cell. Firmness (peak force during first compression), 185 cohesiveness (ratio of force area during second compression to force area during first 186 compression), resilience (ratio of force area down-stroke to force area up-stroke of the first 187 compression), springiness (ratio of time needed for the second compression to that needed for 188 the first compression) and chewiness (product of springiness, cohesiveness and hardness) were 189 calculated from the TPA profiles.

\section{$190 \quad$ 2.9. Differential scanning calorimetry}


To investigate the progress of starch gelatinization as a function of temperature, the portion of non-gelatinized starch crystals was determined in heat treated dough $\left(15 \mathrm{~min} ; 30^{\circ} \mathrm{C}-95^{\circ} \mathrm{C}\right)$ with differential scanning calorimetry (DSC). DSC analyses were performed with a Q1000 DSC (TA Instruments, New Castle, DE, USA) calibrated with indium. Melting enthalpies were calculated using TA Instruments Universal Analysis software. An empty DSC pan served as reference. Freeze dried and milled samples were accurately weighed $(2.5-4.0 \mathrm{mg})$ in aluminum pans (Perkin Elmer,

197 Waltham, MA, USA), deionized water [1:3 (w/w) sample dm:water] was added, pans were 198 hermetically sealed and after equilibration at $0{ }^{\circ} \mathrm{C}$ heated at $4{ }^{\circ} \mathrm{C} / \mathrm{min}$ to $120^{\circ} \mathrm{C}$.

\subsection{Statistical analysis}

All experiments were performed at least in triplicate with statistical analysis (Student T-tests) at a significance level of 95\% with JMP Pro 11.2.0 (SAS institute, Cary, NC, USA).

\section{Results and discussion}

3.1. Temperature dependence of Aq1 activity in the absence and presence of wheat flour extract

Under the above stated assay conditions Aq1 activity was optimal at $65^{\circ} \mathrm{C}$ (Figure 1). Matsuzawa et al. (1988) noted optimal Aq1 activity at $70{ }^{\circ} \mathrm{C}$ on casein at $\mathrm{pH} 10.4$. We here noted a decrease

207 in Aql activity at temperatures exceeding $65^{\circ} \mathrm{C}$. Little if any activity remained at about $90{ }^{\circ} \mathrm{C}$, in 208 line with findings by Matsuzawa et al. (1988).

209 Use of $0.6 \mu$ l WFE in the Aq1 (1.0 U) activity assay resulted in $37 \%, 36 \%, 32 \%$ or $28 \%$ lower 210 activities when incubated at $30^{\circ} \mathrm{C}, 40^{\circ} \mathrm{C}, 50^{\circ} \mathrm{C}$ or $60^{\circ} \mathrm{C}$, respectively. Higher concentrations of 
211 WFE lowered the Aq1 activity even more as the losses in hydrolytic activity at $50{ }^{\circ} \mathrm{C}$ were about

$21287 \%$ or $100 \%$ in the presence of $1.5 \mu$ or $5.0 \mu$ l WFE, respectively. Wheat flour contains different

213 inhibitors of serine peptidases and, more specifically, of subtilisin (Di Maro, et al., 2011; Mundy,

214 Hejgaard, \& Svendsen, 1984; Odani, Koide, \& Ono, 1986; Østergaard, Rasmussen, Roberts, \&

215 Hejgaard, 2000; Poerio, Di Gennaro, Di Maro, Farisei, Ferranti, \& Parente, 2003). Some of the

216 latter may inhibit Aq1 since, as noted above, it is a member of the subfamily of the subtilisin-like

217 peptidases (Matsuzawa, et al., 1988).

218 The loss of peptidase activity when adding $0.6 \mu$ l WFE was lower at $70{ }^{\circ} \mathrm{C}$ and $75^{\circ} \mathrm{C}$ (about $11 \%$

219 and $10 \%$ respectively) than at $50{ }^{\circ} \mathrm{C}$ (about $32 \%$ ). At temperatures of at least $80{ }^{\circ} \mathrm{C}$, all inhibition

220 was lost. When higher levels of WFE were used, incubation at higher temperatures was necessary

221 to decrease the inhibition. When adding $5 \mu \mathrm{l}$ or $25 \mu \mathrm{l}$ WFE, inhibition only started to decrease

222 when the temperature had increased to $70^{\circ} \mathrm{C}$ or $80^{\circ} \mathrm{C}$, respectively. With $5.0 \mu \mathrm{l}$ WFE, $83 \%$ and

$22334 \%$ losses in peptidase activity were measured at respectively $70^{\circ} \mathrm{C}$ and $75^{\circ} \mathrm{C}$.

224 The above allow concluding that inhibition of Aq1 by wheat endogenous inhibitors is temperature

225 dependent. We speculate that the loss of inhibition activity is caused by dissociation of the Aq1-

226 inhibitor complex, denaturation of the inhibitors or a combination of both. Apparently, inhibitor

227 concentration impacts the temperature at which Aq1 is no longer fully inhibited. It has been

228 documented that some serine peptidase inhibitors are inactivated at higher temperature $\left(75^{\circ} \mathrm{C}\right.$

$\left.229-95^{\circ} \mathrm{C}\right)$. For example, barley alpha-amylase subtilisin inhibitor [BASI, Swiss-Prot P07596.2; 90.5\%

230 similarity in amino acid sequence with wheat alpha-amylase subtilisin inhibitor, WASI, Swiss-Prot

231 P16347.1; clustal omega (European Bioinformatics Institute)] loses more than half or even all of 
232 its inhibitory capacity after $10 \mathrm{~min}$ heat-treatment at $80^{\circ} \mathrm{C}$ or $100{ }^{\circ} \mathrm{C}$ respectively (measured at $233 \mathrm{pH}$ 10.0) (Yoshikawa, Iwasaki, Fujii, \& Oogaki, 1976). Another important serine peptidase 234 inhibitor population in wheat flour is that of serpins (Rosenkrands, Hejgaard, Rasmussen, \& Bjorn, 235 1994). For example, Tk-serpin [GenBank BAD85971.1; 31.2\% similarity in amino acid sequence 236 with serpins present in wheat, GenBank CAB52709.1, Clustal Omega (European Bioinformatics 237 Institute)] inhibits subtilisin proteinase K [43\% homology with Aq1 (Kwon, Terada, Matsuzawa, \& 238 Ohta, 1988)] and thermophilic Tk-subtilisin up to $100^{\circ} \mathrm{C}$ (Tanaka, Koga, Takano, \& Kanaya, 2011). 239 Only a fraction serpin inhibitors in wheat flour are extractable with salt solution (Rosenkrands, 240 Hejgaard, Rasmussen, \& Bjorn, 1994). In our work, aqueous extraction of gluten did not recover 241 all Aq1 inhibitors (results not shown). Complex formation and dissociation between Aql and its 242 inhibitors and the impact of temperature thereupon evidently deserve further investigation.

\subsection{Impact of Aqualysin 1 on the gluten network in bread}

244 Aliquots of fermented dough (from recipes with and without Aq1) were heated for 15 min at

245 different temperatures $\left(30^{\circ} \mathrm{C}-95^{\circ} \mathrm{C}\right)$. Next, all proteins were extracted under reducing 246 conditions and subjected to SE-HPLC analysis. In Figure 2.A, the MW profiles of the eluates were 247 divided into high MW (HMW-P, MW exceeding 18.4 k) and low MW (LMW-P, MW lower than $248 \quad 18.4 \mathrm{k}$ ) proteins. This rather arbitrary way of distinguishing between the two different protein 249 classes was chosen because efforts to deconvolute the peaks were unsuccessful. Most GS and 250 gliadins are part of the HMW-P, while at least a significant fraction of albumins and globulins is 251 present in the LMW-P. HMW-P and LMW-P made up about $74 \%$ and $26 \%$ respectively of the total 252 area of the protein extracted from dough which did not contain Aql. That the SE-HPLC profiles of 
253 the SDS-EP from mixed or fermented dough prepared from the Aq1 containing recipe were very 254 similar to each other (results not shown) and to those of the corresponding control samples

255 (Figure 2.B) indicates that Aq1 is not active during these unit operations. In addition, no shift in 256 SDS-EP from HMW-P to LMW-P was noticed as a result of heating from $50^{\circ} \mathrm{C}$ to $75^{\circ} \mathrm{C}$ (Figure 3).

257 The lack of Aq1 activity during mixing, fermentation and heat-treatments up to $75^{\circ} \mathrm{C}$ was expected since the ratio of the levels of inhibitor to that of Aq1 was estimated to be 15 times higher in bread making than that when using the highest concentrations of WFE in the in vitro assay. However, when an aliquot of Aq1 containing dough was heated at temperatures exceeding $80^{\circ} \mathrm{C}$, significant losses of HMW-P occurred. HMW-P indeed decreased by $5 \%( \pm 1 \%), 12 \%( \pm 1 \%)$, $20 \%( \pm 1 \%)$ and $29 \%( \pm 1 \%)$ as a result of heating at $80{ }^{\circ} \mathrm{C}, 85^{\circ} \mathrm{C}, 90^{\circ} \mathrm{C}$ and $95^{\circ} \mathrm{C}$, respectively, 263 and the losses were compensated by increases in extractable LMW-P. The clear shift in MW 264 distribution indicates that partial hydrolysis of gluten proteins started around $80^{\circ} \mathrm{C}$ during bread 265 making. Aq1 probably became active again after dissociation from and/or inactivation of its 266 inhibitor(s). In activity measurements with $p$-nitroanilide substrate, Aq1 was optimally active at $26765^{\circ} \mathrm{C}$ (Figure 1). When in the assay WFE $(25 \mu \mathrm{l})$ was added, the highest activity was measured at $26885{ }^{\circ} \mathrm{C}$, while in this bread-like system the highest Aq1 activity was noticed at about $95^{\circ} \mathrm{C}$ (largest 269 decrease in HMW-P levels, Figure 3). In contrast, no Aq1 activity was measured at temperatures 270 exceeding $90^{\circ} \mathrm{C}$ under the in vitro assay conditions. As a result of heating control dough for $27115 \mathrm{~min}$ at $95^{\circ} \mathrm{C}, 27 \%( \pm 1 \%)$ of the total SDS-EP was extractable under reducing conditions as 272 LMW-P. When the same experiment was done with Aql containing dough, the result was $56 \%$ ( \pm $2731 \%$ ) of the total SDS-EP level. Furthermore, in the standard bread making recipe (13 min at 
$274232^{\circ} \mathrm{C}$ ), the SDS-EP level of LMW-P increased from $26 \%( \pm 1 \%)$ (without Aq1) to $67 \%( \pm 5 \%)$ when

275 Aq1 was included.

276 Protein extractions were also performed under non-reducing conditions. Due to cross-linking of 277 gluten proteins during baking, the level of SDS-EP decreased from $90 \%( \pm 4 \%)$ in control dough 278 to $24 \%$ ( $\pm 1 \%$ ), in line with results of Lagrain et al. (2005). In the case of the Aq1 containing recipe, 279 the corresponding SDS-EP values were $91 \%( \pm 3 \%)$ and $43 \%( \pm 1 \%)$ respectively (Figure 2.B). That 280 the protein extractability under non-reducing conditions was $19 \%$ higher as a result of Aq1 use 281 points to the presence of hydrolysed fragments in the protein network of the former and thus to 282 a less coherent gluten network.

283 To better understand the impact of Aq1 during heat-treatment on gluten properties, the viscosity 284 of gluten suspensions was monitored while executing a temperature-time profile both in its 285 absence and in its presence (Figure 4). The viscosity of gluten suspensions decreased when the 286 temperature increased from $40^{\circ} \mathrm{C}$ up to $95^{\circ} \mathrm{C}$. This is comparable to the findings of Lagrain et al.

287 (2005). None of the levels of Aq1 tested changed the viscosity profile significantly during this 288 heating step (Figure 4). Commercial gluten also contained Aq1 inhibitors (enzyme activity results 289 not shown). The latter postponed Aq1 activity during this first heating stage resulting in 290 insufficient gluten hydrolysis to change the viscosity. The viscosity increased during the holding 291 phase at $95^{\circ} \mathrm{C}$ (Figure 4). This can be attributed to crosslinking of gluten proteins mainly by SH292 SS-exchange reactions (Lagrain, Thewissen, Brijs, \& Delcour, 2008). Lagrain et al. (2005) noted a 293 steep viscosity increase when almost all glutenin and more than half of the gliadin proteins are 294 covalently incorporated in the gluten network. The increase in viscosity during the holding phase 
at $95{ }^{\circ} \mathrm{C}$ was less pronounced when increasing concentrations of Aq1 were used (Figure 4). At the end of the holding phase, the maximal peak viscosity was significantly lower when higher concentrations of Aq1 were used. Aq1 activity during this heat-treatment resulted in a weakened gluten network.

Combined, the above RVA and protein extractability data allow concluding that Aq1 weakens and reduces the coherence of the gluten network during heating. Even though Aq1 is not active at temperatures below $80^{\circ} \mathrm{C}$, it can still significantly impact the gluten network formed as a result of bread making. As Aq1 becomes active during the later stages of bread baking, the relative contribution of post structure setting changes in the gluten network on the texture and structure of bread can be investigated.

\subsection{Impact of Aq1 on the texture of fresh bread crumb}

Inclusion of Aq1 in the standard bread making recipe impacted neither the volume of the resulting breads (Table 1) nor did it cause visually observable differences in crumb structure

(Figure 5.A). However, it lowered crumb firmness, cohesiveness, springiness, resilience and chewiness significantly (Table 1). Also, the crumb disintegrated more easily. The large discrepancy between the significant impact on the gluten MW distribution and protein extractability described in Section 3.2 and the rather small changes in texture properties suggest a major role for starch in bringing about bread crumb texture.

DSC analysis showed that amylopectin in dough starts to melt at about $60{ }^{\circ} \mathrm{C}$ and that almost all crystals had melted when the temperature reached $85{ }^{\circ} \mathrm{C}$ (Figure 3). Addition of Aql had no impact on the amylopectin melting temperature (results not shown). The enzyme became active 
316 after starch gelatinization started and is presumably active in the temperature range wherein

317 significant gluten protein crosslinking occurs. A. P. Singh et al. (2005) have suggested that starch

318 gelatinization stiffens the walls of the gas cells and limits gas cell expansion which subsequently

319 impacts bread loaf volume. As starch gelatinization controls the end point for gas cell expansion,

320 it can also influence crumb texture. Furthermore, it transforms visco-elastic dough into elastic

321 crumb (Lagrain, Leman, Goesaert, \& Delcour, 2008; Rouillé, Chiron, Colonna, Della Valle, \&

322 Lourdin, 2010; A. P. Singh \& Bhattacharya, 2005).

323 When peptidases are active prior to starch gelatinization, gas cells can in some instances expand

324 better than in control bread making resulting in larger volume and softer crumb (Caballero,

325 Gomez, \& Rosell, 2007; Indrani, Prabhasankar, \& Venkateswara Rao, 2003). Since Aq1 only

326 became active after both starch gelatinization and the transition of dough foam into crumb, it

327 did not impact the gas cell expansion. Therefore, no changes in specific volume were noted. Only

328 small changes in texture were noted which points to the importance of the starch matrix for

329 bread texture. Further evidence that starch is an important structure determining component is

330 that application of thermostable Bacillus subtilis alpha-amylase and Bacillus stearothermophilus

331 maltogenic amylase in bread making largely impact the macroscopic crumb structure and initial

332 crumb firmness, respectively (Lagrain, Leman, Goesaert, \& Delcour, 2008).

\subsection{Baking of model systems}

334 The impact of gluten crosslinking and starch gelatinization on crumb structure was further

335 investigated by preparing two unfermented dough model systems containing gluten and water

336 (GD) or gluten, starch and water (GSD) with and without addition of Aq1. GD expanded 
337 enormously during baking but collapsed upon cooling. Irregular shaped GD "breads" were 338 formed (Figure 5.B). In these model systems, the expansion was mainly due to water 339 evaporation. GD containing Aq1 expanded to a smaller extent during baking than control GD.

340 Probably because the expansion was less pronounced for GD containing Aq1 than for control GD,

341 the former did not visually collapse during cooling. In the GD containing Aql, the peptidase 342 activity during baking weakened the gluten network which limited gas cell expansion upon water 343 evaporation. Furthermore, addition of Aql caused the "crumb" of GD to be softer and more 344 crumbly than that of control GD. When starch was used along with gluten, model dough systems 345 with comparable volumes and shapes were obtained (Figure 5.C). The GSD system prepared with 346 Aq1 addition was slightly more crumbly and less coherent than its control counterpart. Starch 347 gelatinization in the control GSD prevented enormous expansions and collapse of the gas cells 348 resulting in less open crumb structures and regular shapes. Starch gelatinization minimized the 349 impact of gluten network formation on the volume and structure of these model systems. 350 Nevertheless, gluten seemed important for the coherence of the final product as Aq1 use 351 increased the crumbliness of the baked product.

352 Gluten protein hydrolysis at temperatures exceeding $80^{\circ} \mathrm{C}$ impacted texture only to a small 353 extent and had no impact on the specific volume or macroscopic appearance of bread crumb 354 (Table 1 and Figure 5.C). Whereas gluten hydrolysis prior to starch gelatinization largely impacts 355 bread quality, its impact is less pronounced once the bread structure is set by gelatinized starch. 356 The main role of the thermoset gluten network seems to be its contribution to the coherence of 357 the final bread structure. 
359 While proteins in WFE limit the activity of Aq1 at lower temperatures, they no longer do so at 360 high temperatures. The mechanism(s) by which proteinaceous inhibitors impact Aql activity are 361 temperature dependent. To the best of our knowledge, our report is the first to demonstrate the

362 food application of a heat-reversible inhibition of a peptidase or, for that matter, an enzyme by 363 proteinaceous inhibitors. Application of Aq1 in wheat bread making avoids gluten protein 364 hydrolysis during mixing and fermentation and enables it at about $80^{\circ} \mathrm{C}$ in the baking process. 365 For the first time, it was possible to study the impact of heat-induced gluten network formation 366 on the structure and texture of bread. Aq1 was indeed successfully used as a tool in bread making 367 to study the impact of gluten network formation on bread crumb texture. Application of Aq1 had 368 no impact on bread specific volume and only a rather small but still significant impact on the 369 firmness of bread crumb. Aq1 peptidase activity during baking was responsible for a more 370 crumbly and less coherent crumb structure than in control bread making. Of the physico371 chemical changes during the baking phase, starch gelatinization is the main contributor to the 372 overall bread texture and gluten polymerization seems to be important for the coherence of its 373 crumb.

\section{Acknowledgements}

375 This work is part of the Methusalem programme 'Food for the Future' at KU Leuven. The authors 376 thank Puratos (Groot-Bijgaarden) for financial support of the Peptibread project at KU Leuven. K. 377 Brijs acknowledges the Industrial Research Fund (KU Leuven, Leuven, Belgium) for a position as 
378 Industrial Research Manager. B. Vangeneugden and G. Gryp are thanked for technical assistance.

379 J. A. Delcour is W. K. Kellogg Chair in Cereal Science and Nutrition at KU Leuven.

380 Note:

381 Conflicts of interest: none

382 


\section{References}

AACC. (1999). Approved Methods of American Association of Cereal Chemists (11th ed.). St. Paul, MN, USA.: AACC International.

AOAC. (1995). Methods of Association of Official Analytical Chemists (16th ed.). Washington, DC, USA: AOAC International.

Bourne, M. C. (1978). Texture profile analysis. Food Technology, 62-72.

Caballero, P. A., Gomez, M., \& Rosell, C. M. (2007). Improvement of dough rheology, bread quality and bread shelf-life by enzymes combination. Journal of Food Engineering, 81(1), 42-53.

D'Ovidio, R., \& Masci, S. (2004). The low-molecular-weight glutenin subunits of wheat gluten. Journal of Cereal Science, 39, 321-339.

Delcour, J. A., \& Hoseney, R. C. (2010). Principles of Cereal Science and Technology (3rd ed.). St. Paul, MN, USA: AACC International Press.

Delcour, J. A., Joye, I. J., Pareyt, B., Wilderjans, E., Brijs, K., \& Lagrain, B. (2012). Wheat gluten functionality as a quality determinant in cereal-based food products. Annual Review of Food Science and Technology, 3, 469-492.

Di Maro, A., Farisei, F., Panichi, D., Severino, V., Bruni, N., Ficca, A. G., Ferranti, P., Capuzzi, V., Tedeschi, F., \& Poerio, E. (2011). WCl, a novel wheat chymotrypsin inhibitor: purification, primary structure, inhibitory properties and heterologous expression. Planta, 234(4), 723-735.

Fan, J., Mitchell, J. R., \& Blanshard, J. M. V. (1999). A model for the oven rise of dough during baking. Journal of Food Engineering, 41, 69 - 77.

Finney, K. F. (1984). An optimized, straight-dough, bread-making method after 44 years. Cereal Chemistry, 61(1), 20-27.

Goesaert, H., Brijs, K., Veraverbeke, W. S., Courtin, C. M., Gebruers, K., \& Delcour, J. A. (2005). Wheat flour constituents: how they impact bread quality, and how to impact their functionality. Trends in Food Science \& Technology, 16(1-3), 12-30.

Indrani, D., Prabhasankar, P., Rajiv, J., \& Venkateswara Rao, G. (2003). Scanning electron microscopy, rheological characteristics, and bread-baking performance of wheat-flour dough as affected by enzymes. Sensory and Nutritive Qualities of Food, 68(9), 2804 - 2809.

Kwon, S. T., Terada, I., Matsuzawa, H., \& Ohta, T. (1988). Nucleotide-sequence of the gene for AqualysinI (a thermophilic alkaline serine protease) of Thermus-aquaticus Yt-1 and characteristics of the deduced primary structure of the enzyme. European Journal of Biochemistry, 173(3), 491-497.

Lagrain, B., Brijs, K., Veraverbeke, W. S., \& Delcour, J. A. (2005). The impact of heating and cooling on the physico-chemical properties of wheat gluten-water suspensions. Journal of Cereal Science, 42, 327-333.

Lagrain, B., Leman, P., Goesaert, H., \& Delcour, J. A. (2008). Impact of thermostable amylases during bread making on wheat bread crumb structure and texture. Food Research International, 41, 819-827.

Lagrain, B., Thewissen, B. G., Brijs, K., \& Delcour, J. A. (2008). Mechanism of gliadin-glutenin cross-linking during hydrothermal treatment. Food Chemistry, 107(2), 753-760.

Lefebvre, J., Popineau, Y., Deshayes, G., \& Lavenant, L. (2000). Temperature-induced changes in the dynamic rheological behavior and size distribution of polymeric proteins for glutens from wheat near-isogenic lines differing in HMW glutenin subunit composition. Cereal Chemistry, 77(2), 193201.

Lindsay, M. P., \& Skerritt, J. H. (1999). The glutenin macropolymer of wheat flour doughs: structurefunction perspectives. Trends in Food Science \& Technology, 10, 247-253.

Mathewson, P. R. (2000). Enzymatic activity during bread baking. Cereal Foods World, 45(3), 98-101. 
Matsuzawa, H., Tokugawa, K., Hamaoki, M., Mizoguchi, M., Taguchi, H., Terada, I., Kwon, S. T., \& Ohta, T. (1988). Purification and characterization of Aqualysin-I (a thermophilic alkaline serine protease) produced by Thermus-aquaticus Yt-1. European Journal of Biochemistry, 171(3), 441-447.

Megan, P. L., \& Skerritt, J. H. (1999). The glutenin macropolymer of wheat flour doughs: structurefunction perspectives. Trends in food Science and Technology, 10, 247-253.

Mundy, J., Hejgaard, J., \& Svendsen, I. (1984). Characterization of a bifunctional wheat inhibitor of endogenous alpha-amylase and subtilisin. Febs Letters, 167(2), 210-214.

Odani, S., Koide, T., \& Ono, T. (1986). Wheat-germ trypsin-inhibitors - isolation and structural characterization of single-headed and double-headed inhibitors of the Bowman-Birk type. Journal of Biochemistry, 100(4), 975-983.

$\emptyset$ stergaard, H., Rasmussen, S. K., Roberts, T. H., \& Hejgaard, J. (2000). Inhibitory serpins from wheat grain with reactive centers resembling glutamine-rich repeats of prolamin storage proteins. The Journal of Biological Chemistry, 275, 33272-33279.

Poerio, E., Di Gennaro, S., Di Maro, A., Farisei, F., Ferranti, P., \& Parente, A. (2003). Primary structure and reactive site of a novel wheat proteinase inhibitor of subtilisin and chymotrypsin. Biological Chemistry, 384(2), 295-304.

Rawlings, N. D., Barrett, A. J., \& Bateman, A. (2010). MEROPS: the peptidase database. Nucleic Acids Research, 38, 227-233.

Rosenkrands, I., Hejgaard, J., Rasmussen, S. K., \& Bjorn, S. E. (1994). Serpins from wheat-grain. Febs Letters, 343(1), 75-80.

Rouillé, J., Chiron, H., Colonna, P., Della Valle, G., \& Lourdin, D. (2010). Dough / crumb transition during French bread baking. Journal of Cereal Science, 52, 161 - 169.

Scanlon, M. G., \& Zghal, M. C. (2001). Bread properties and crumb structure. Food Research International, 34(10), 841-864.

Schofield, J. D., Bottomley, R. C., Timms, M. F., \& Booth, M. R. (1983). The effect of heat on wheat gluten and involvement of sulphydryl-disulphide interchange reactions. Journal of Cereal Science, 1, 241-253.

Shewry, P. R., \& Tatham, A. S. (1997). Disulphide bonds in wheat gluten proteins. Journal of Cereal Science, 25, 207-227.

Shewry, P. R., Tatham, A. S., Forde, J., Kreis, M., \& Miflin, B. J. (1986). The classification and nomenclature of wheat gluten proteins - a reassessment. Journal of Cereal Science, 4(2), 97-106.

Singh, A. P., \& Bhattacharya, M. (2005). Development of dynamic modulus and cell opening of dough during baking. Journal of Texture Studies, 36, 44-67.

Singh, H., \& MacRitchie, F. (2001). Application of polymer science to properties of gluten. Journal of Cereal Science, 33, 231-243.

Song, Y., \& Zheng, Q. (2007). Dynamic rheological properties of wheat flour dough and proteins. Trends in Food Science \& Technology, 18, 132-138.

Tanaka, S., Koga, Y., Takano, K., \& Kanaya, S. (2011). Inhibition of chymotrypsin- and subtilisin-like serine proteases with Tk-serpin from hyperthermophilic archaeon Thermococcus kodakaraensis. Biochimica Et Biophysica Acta-Proteins and Proteomics, 1814(2), 299-307.

Veraverbeke, W. S., \& Delcour, J. A. (2002). Wheat protein composition and properties of wheat glutenin in relation to breadmaking functionality. Critical Reviews in Food Science and Nutrition, 42(3), 179-208.

Wieser, H. (2007). Chemistry of gluten proteins. Food Microbiology, 24, 115-119.

Yoshikawa, M., Iwasaki, T., Fujii, M., \& Oogaki, M. (1976). Isolation and some properties of a subtilisin inhibitor from barley. Journal of Biochemistry, 79, 765-773. 
476 Table 1: Texture profile data from double compression of bread crumb by $50 \%$ from control

477 bread and bread produced from an aqualysin 1 (Aq1) containing recipe (control + Aql). Values

478 between brackets represent standard deviations. All listed parameters except the specific

479 volumes were significantly lower for crumb from control + Aq1 than for crumb from control $(\alpha=$ $480 \quad 0.05)$

481

482 Figure 1: The decrease in level of $p$-nitroaniline released from N-succinyl-ala-ala-pro-phe- $p$ 483 nitroanilide by aqualysin 1 with increasing concentrations of wheat flour extract (WFE) (0.0 $\mu$, $4840.6 \mu \mathrm{l}, 1.5 \mu \mathrm{l}, 5.0 \mu \mathrm{l}$ and $25.0 \mu \mathrm{l}$, areas indicated by grey-scales starting from white to dark-grey) 485 for various incubation temperatures. Standard deviations are given with error bars.

487 Figure 2: SE-HPLC profiles of proteins extracted from control bread crumb (black line) and from 488 bread crumb produced from an aqualysin 1 (Aq1) containing recipe (grey line) under reducing 489 conditions (A). Eluted proteins were rather arbitrarily divided into high MW (HMW-P, MW > 18.4 $490 \mathrm{k})$ and low MW (LMW-P, MW < 18.4 k).

491 SE-HPLC profiles of proteins extracted from fermented dough samples (dotted lines) and breads

492 (full lines) from control (black lines) and an Aq1 containing recipe (grey) under non-reducing 493 conditions (B). The most abundant gluten protein fractions present in the different peaks are 494 indicated.

495

496 Figure 3: Levels of high molecular weight proteins [HMW-P, molecular weight (MW) > 18.4 k, 497 dark grey] and low molecular weight proteins (LMW-P, MW $<18.4$ k, light grey) extractable in 
498 SDS containing medium under reducing conditions from unheated and heat-treated (15 min, 50 499 to $95^{\circ} \mathrm{C}$ range) pieces of fermented aqualysin 1 (Aq1) dough (stacked columns). The scatter line 500 indicates the percentages of gelatinized starch in the same samples.

501

502 Figure 4: Rapid visco analyzer profiles (grey) of gluten suspensions in water [17\% $(\mathrm{w} / \mathrm{w})$ on 503 protein basis, total weight of $25.00 \mathrm{~g}$ ] without aqualysin 1 (Aq1) (full line) or addition of $47 \mathrm{U}$ 504 (dotted line) or $94 \mathrm{U}$ (striped line) Aq1, subjected to a specific temperature-time profile (black). 505

506 Figure 5: Control and aqualysin 1 (Aq1) containing (control + Aq1) model bread systems 507 consisting of bread loaves made according to a straight-dough method (A), $100 \%$ wheat gluten 508 (B) or $25 \%$ wheat gluten and $75 \%$ commercial starch (C). 509 510 